\title{
The Analysis of Electrolyte Levels on Hypertensive Patients in Noongan Regional General Hospital, North Sulawesi, Indonesia
}

\author{
Diana Shintawati Purwanto, "*, Yanti Meilen Mewo ${ }^{1}$, Edmond Leonard Jim², \\ Richardo Jordan Laloan ${ }^{3}$, Joice Nancy Ansje Engka ${ }^{4}$, Billy Johnson Kepel ${ }^{5}$ \\ ${ }^{1}$ Department of Biochemistry, Sam Ratulangi University, Manado, Indonesia \\ ${ }^{2}$ Department of Cardiovascular Medicine, Sam Ratulangi University, Manado, Indonesia \\ ${ }^{3}$ Clinical Clerkship Program, Sam Ratulangi University, Manado, Indonesia \\ ${ }^{4}$ Department of Physiology, Sam Ratulangi University, Manado, Indonesia \\ ${ }^{5}$ Department of Chemistry, Sam Ratulangi University, Manado, Indonesia \\ Email address: \\ dianashintapurwanto@unsrat.ac.id (D. S. Purwanto) \\ ${ }^{*}$ Corresponding author
}

\section{To cite this article:}

Diana Shintawati Purwanto, Yanti Meilen Mewo, Edmond Leonard Jim, Richardo Jordan Laloan, Joice Nancy Ansje Engka, Billy Johnson Kepel. The Analysis of Electrolyte Levels on Hypertensive Patients in Noongan Regional General Hospital, North Sulawesi, Indonesia. Science Journal of Clinical Medicine. Vol. 8, No. 5, 2019, pp. 54-60. doi: 10.11648/j.sjcm.20190805.12

Received: September 19, 2019; Accepted: September 30, 2019; Published: October 15, 2019

\begin{abstract}
Hypertension is one of the major risk factors of cardiovascular diseases, in addition to hypercholesterolemia and diabetes mellitus. Approximately 95\% cases of hypertension in Indonesia is essential hypertension that remains unknown for the etiology and tends to be multifactorial causes. Electrolyte imbalance is thought as one of the prominent underlying mechanisms of hypertension. Electrolyte imbalance can cause serious and life-threatening cardiovascular problems. This study aimed to find out the association between electrolytes levels (serum sodium, potassium, chloride, and total calcium) and blood pressure in hypertensive patients. This was a cross-sectional study that conducted on June-August 2019 at Noongan Regional General Hospital, Minahasa Regency, North Sulawesi, Indonesia. Demographic data such as age, sex, symptoms, salt diet, and consumption of antihypertensive drugs were collected, and then physical examinations including systolic and diastolic blood pressures and body mass index (BMI) were performed. One Sample Kolmogorov-Smirnov and Spearman Rank tests were used for bivariate analysis. There is significant dirrect correlation between serum sodium levels and systolic blood pressure, and an inverse relationship with diastolic blood pressure. As for potassium, there is an inverse relationship between serum potassium levels with systolic and diastolic blood pressures, but not significant. There is a direct correlation between serum chloride levels and systolic blood pressure, and an inverse relationship with diastolic pressure, but not significant. For total calcium, there is a direct correlation between serum total calcium levels and systolic and diastolic blood pressures, but not significant. In this study, we found out only sodium has a significant correlation with blood pressure, while other electrolytes have a correlation but are not significant.
\end{abstract}

Keywords: Electrolyte, Hypertension, Sodium, Potassium, Chloride, Total Calcium

\section{Introduction}

Hypertension is a medical condition characterized by high blood pressure that occurs consistently and persistently. Hypertension is one of the risk factors of cardiovascular disease, in addition of hypercholesterolemia and diabetes mellitus [1]. High pressure on artery walls in hypertensive individuals can damage the arteries and also affect physiological functions of many organs. Uncontrolled blood pressure eventually leads to various complications such as coronary artery disease, heart attack, stroke, congestive heart failure, renal insufficiency, and chronic kidney disease [2]. 
About $70 \%$ individuals who has first time heart attack prior and $80 \%$ individuals who is diagnosed with stroke has high blood pressure unconsciously. World Health Organization (WHO) has stated that hypertension is one of the causes of premature death worldwide. It is estimated that hypertension has caused about 7.5 million deaths, which is equivalent to $12.8 \%$ of total annual deaths globally [3]. Approximately 77.9 million American adults and 970 million people around the world have high blood pressure. It is predicted that by 2025 , there will be 1.56 billion adults suffering from hypertension [4]. The incidence of hypertension is equal between male and female, that can only be differ with age. The prevalence of high blood pressure on people under the age of 45 are more frequent suffered by male than female, whereas high blood pressure on people over or equal to the age of 65 are generally suffered by female than male [5].

According to statistical data from World Health Organization in 2014, the prevalence of hypertension for male and female in Indonesia is $24 \%$ and $22.6 \%$, respectively [6]. According to the result of the Indonesia Basic Health Research 2018, the prevalence of hypertension based on physician diagnosis and consuming anti-hypertension drugs among Indonesian residents $\geq 18$ years-old was $8.8 \%$, meanwhile data by province pointed out that North Sulawesi was ranked first out of a total 34 provinces in Indonesia, with the highest percentage of 13.5\% [7]. Data from the North Sulawesi Public Health Service showed the results of blood pressure measurement on the population aged $\geq 18$ years-old across all cities and regencies in North Sulawesi, and found out that the number of hypertensive patients was 73,108 (38.4\%), while data for high blood pressure by sex in the population aged $\geq 18$ years in 2016 showed three cities/regencies with a high prevalence of hypertension patients were Bolaang Mongondow Timur (58.5\%), Minahasa (54.7\%), and Kotamobagu City (30.3\%) [8].

The pathogenesis of hypertension can be due to various mechanisms. One of its mechanisms is electrolyte imbalance. Electrolyte and water are the most important components to maintain body's physiological fluid. Electrolytes are compounds that affect many functional aspects of the body such as balancing the amount of fluid inside and outside the body, and play an important role in muscle contractions and heart functions. Without fluid and electrolyte balance, body cells are lack of its important electrical conductivity that is required to generates cellular energy. Electrolyte imbalance affects the body and can cause a serious cardiovascular condition and be life-threatening [9].

Hypertension occurs due to many factors such as genetic, environmental, or both. Environmental factor which has the most powerful impact towards blood pressure is food consumption or diet, in which this factor plays a role in homeostasis of blood pressure. Hypertensive patients, in most cases, tend to have an unhealthy food diet due to change in lifestyle. The easy for individuals to get food, the more unhealthy diet they get. Fast food tends to cause consumption of vegetables and fiber to be less, on the contrary salt, fat, and sugar remain high, which in turn increase calories itself [10]. Higher salt intake can cause fluid retention and this leads to increase blood volume. Heart will work harder by pumping the excessive blood volume throughout the narrowed walls and results in a condition of high blood pressure. In contrast to sodium, potassium is more relatable to the condition that decreases the blood pressure. Principally, potassium is found in the body cells. Potassium function is to fit up sodium function itself. Potassium itself plays an important role in maintaining fluid and electrolytes balances, as well as acid base [11].

Approximately $95 \%$ cases of hypertension in Indonesia is essential (or primary) hypertension that remains unknown for the etiology and tends to be multifactorial causes [6] Hypothetically, essential hypertension is thought to be multifactorial causes such as obesity, diabetes mellitus, aging, emotional stress, sedentary lifestyle also as well as described previously is low consumption of potassium [12]. Other risk factors that are thought to possibly cause hypertension are alcoholism, smoking cigarette, obstructive sleep apnea, dyslipidemia, high uric acid, race and last but not least is family history [13].

Hypertension is well-known as 'Silent Killer' because people are typically unaware that they have high blood pressure and due to it has no specific warning or serious symptoms in the first stage of disease. Only a small amount of people may experience the symptoms such as headache, palpitation, lethargic, vomit, dizziness, epistaxis or nosebleed. Headache in hypertensive patients is specifically called as 'hypertensive headache' that occurs particularly in the morning and localized posteriorly on occipital region. Generally, when the symptoms aforementioned occur, that would be the manifestation of higher blood pressure that is in life-threatening stage [14].

The cause of persistent high blood pressure in essential hypertensive patients is still remains unknown in many studies. It is also lack of studies which correlating between electrolyte levels (sodium, potassium, chloride and total calcium) and hypertension. This study aimed to find out the correlation between electrolyte levels (sodium, potassium, chloride, and total calcium) and blood pressure (systolic and diastolic) in hypertensive patients in Noongan Regional General Hospital, Minahasa Regency.

\section{Materials and Methods}

\subsection{Ethical Approval}

This study was approved by the Medical Research Ethics Committee of R. D. Kandou General Hospital (Ethical Approval No. 058/EC-KEPK/V/2019). Written informed consent for participating in the study was obtained from all of the patients or accompanying close relatives.

\subsection{Study Design and Study Timeline}

A cross-sectional study was conducted at Noongan 
Regional General Hospital, Minahasa Regency. This study site is a regency hospital located around $50 \mathrm{~km}$ from Manado, the capital city of North Sulawesi, at the northeastern part of Indonesia. This study only analyzed the correlation between blood pressure of hypertensive patients and electrolyte levels, without giving any interventions or treatments to all subjects. The timeline of sample collection was started in June 2019 and finished in August 2019.

\subsection{Populations and Sampling Methodology}

Populations were all inpatients and outpatients with high blood pressure, in Noongan Regional General Hospital, Minahasa Regency. Sample collection used total sampling method, in which all subjects examined during the study period and met the inclusion and exclusion criteria and willing to take part in this study, were included. A prior written approval was given by participant before undergoing the procedure. Demographic data such as age, sex, symptoms, salt diet, and consumption of antihypertensive drugs were collected by professional nurses. Then, physical examinations including systolic and diastolic blood pressures (SBP, DBP) and body mass index (BMI) were performed. Blood pressure measurement was taken two times of the selected subjects by using mercury sphygmomanometer, and the average of two reading scores was used. Measurement of electrolytes (sodium, potassium and chloride levels) was carried out at the Noongan Regional General Hospital's laboratory; meanwhile the measurement of total calcium was carried out in Patra Laboratory, Manado.

\subsection{Statistical Data Analysis}

Data analysis was performed by using 22nd version of Statistical Package for Social Sciences (SPSS 22). Univariate analysis was conducted to have data results descriptively of independent variables (sodium, potassium, chloride and total calcium). Meanwhile, bivariate analysis was conducted to determine the correlation between independent variables (serum sodium, potassium, chloride and total calcium) and dependent variables (systolic and diastolic blood pressure). The normality of each variable was calculated using the One Sample Kolmogorov-Smirnov test, and it had a normal distribution if the value of $\mathrm{p}>0.05$. Subsequently, the correlation between electrolyte levels and blood pressure was examined using Spearman Rank correlation test.

\section{Results}

\subsection{Demographic Data}

The patient characteristics are described in Table 1 . Seventy-three blood specimens were collected from patients with clinically diagnosed as hypertension. The age of the patients were between 21 to 85 years and $35.61 \%(n=26)$ with aged $\geq 65$ years, with an average age of $57.7 \pm 13.66$ years. Thirty-three of 73 patients were males $(45.20 \%)$. It was found that the majority of patient symptoms were headache $(42.47 \%)$, dizziness $(27.40 \%)$, and extremity weakness $(24.66 \%)$. We observed that majority of subjects $(84.93 \%)$ were hypertension grade I patients based on JNCVIII classification.

Table 1. Patient characteristics (demographic and clinical).

\begin{tabular}{|c|c|c|}
\hline Characteristics & Category & $\mathbf{N}(\%)$ \\
\hline \multirow{5}{*}{ Age (year) } & $18-24$ & $2(2.74)$ \\
\hline & $25-34$ & $2(2.74)$ \\
\hline & $35-44$ & $8(10.96)$ \\
\hline & $55-64$ & $20(27.40)$ \\
\hline & $\geq 65$ & $26(35.61)$ \\
\hline Sex & Male & $33(45.20)$ \\
\hline \multirow{10}{*}{ Symptoms } & Headache & $31(42.47)$ \\
\hline & Dizziness & $20(27.40)$ \\
\hline & Extremity weakness & $18(24.66)$ \\
\hline & Fever & $13(17.81)$ \\
\hline & Nausea & $9(12.33)$ \\
\hline & Vomit & $9(12.33)$ \\
\hline & Myalgia & $9(12.33)$ \\
\hline & Neck pain & $2(2.74)$ \\
\hline & Alteration of mental status & $2(2.74)$ \\
\hline & Others (shortness of breath, diarrhea, shivering) & $9(12.33)$ \\
\hline \multirow{2}{*}{ Salt consumption } & Often & $49(67.12)$ \\
\hline & Rarely & $24(32.88)$ \\
\hline \multirow{3}{*}{ Body Mass Index $\left(\mathrm{kg} / \mathrm{m}^{2}\right)$} & Normal (18.5-24.9) & $34(46.58)$ \\
\hline & Overweight $(25-29.9)$ & $38(52.05)$ \\
\hline & Obese $(\geq 30)$ & $1(1.37)$ \\
\hline \multirow{2}{*}{ Hypertension patients classification (JNC VIII) } & Grade I & $62(84.93)$ \\
\hline & Grade II & $11(15.07)$ \\
\hline
\end{tabular}




\subsection{Sodium, Potassium, Chloride, and Total Calcium Levels}

The average systolic blood pressure in hypertensive subjects was $147.47 \pm 11.28$ and the diastolic blood pressure was $106.58 \pm 9.89$. Table 2 shows the mean and median of sodium, potassium, chloride, and total calcium electrolyte concentrations. Based on statistical analysis, the sodium and chloride concentrations had a normal distribution, while potassium and total calcium had an abnormal distribution data.

Table 2. Sodium, potassium, chloride, and total calcium levels.

\begin{tabular}{llllll}
\hline Electrolytes & Unit & Mean & Median & Standard deviation & Minimum \\
\hline Sodium & $\mathrm{mmol} / \mathrm{L}$ & 135.14 & 136 & 7.738 & 106 \\
Potassium & $\mathrm{mmol} / \mathrm{L}$ & 3.86 & 3.9 & 0.84 & 147 \\
Chloride & $\mathrm{mmol} / \mathrm{L}$ & 99.25 & 100 & 6.91 & 5.9 \\
Total Calcium & $\mathrm{mg} / \mathrm{dL}$ & 9.22 & 9.24 & 1.03 & 68 \\
\hline
\end{tabular}

\subsection{Correlation Test Between Electrolyte Levels and Blood Pressure}

Correlation test between electrolytes (sodium, potassium, chloride, and total calcium) and blood pressures (systolic and diastolic) in hypertension patients in this research used the Spearman correlation test. The results of this correlation are shown in Table 3.

Table 3. Correlation test results between electrolytes levels and blood pressure.

\begin{tabular}{llll}
\hline \multirow{2}{*}{ Electrolyte } & \multicolumn{2}{l}{ Systolic blood pressure } & \multicolumn{2}{c}{ Diastolic blood pressure } \\
\cline { 2 - 4 } & Correlation coefficient (rs) & Sig. (p) & Correlation coefficient (rs) \\
\hline Sodium & 0.100 & 0.042 & -0.284 \\
Potassium & -0.064 & 0.591 & -0.084 \\
Chloride & 0.066 & 0.579 & -0.090 \\
Total Calcium & 0.044 & 0.711 & 0.015 \\
\hline
\end{tabular}

It is described in Table 3 that the correlation between systolic blood pressure and sodium level has a value of rs $=$ 0.100 , which can be categorized as having a very weak and positive correlation strength (directly proportional), which means if sodium levels in blood serum are high then systolic blood pressure will also increase. Based on the significance test, the result shows $p$-value $=0.042(p<0.05)$, therefore the null hypothesis is rejected meaning that there is a significant relationship between systolic blood pressure and sodium level. The correlation between systolic blood pressure and potassium levels has a value of $\mathrm{rs}=-0.064$ which can be categorized as having a very weak and negative correlation strength (inversely proportional), which means that if the potassium levels in blood serum are high then the systolic blood pressure will decrease. Based on the significance test, the result shows $p$-value $=0.591(p>0.05)$ and so the null hypothesis is accepted, meaning that there is no significant relationship between systolic blood pressure and potassium.

The correlation of systolic blood pressure and chloride levels has a value of $r s=0.066$ which can be categorized as having a very weak and positive correlation strength (directly proportional), which means that if the chloride levels in the blood serum are high then the systolic blood pressure will also increase. Based on the significance test, the result shows $p$-value $=0.579(p>0.05)$, so the null hypothesis is accepted meaning that there is no significant relationship between systolic blood pressure and chloride. The correlation of systolic blood pressure and total calcium levels has a value of rs $=0.044$ which can be categorized as having a very weak and positive correlation strength (directly proportional), which means that if total calcium levels in the blood serum are high then systolic blood pressure will also increase. Based on the significance test the result shows $p$-value $=$ 0.711 ( $p>0.05)$, and so the null hypothesis is accepted, meaning that there is no significant relationship between systolic blood pressure and total calcium.

The correlation between diastolic blood pressure and sodium levels has a value of $\mathrm{rs}=-0.284$ which can be categorized as having weak and negative correlation strengths (inversely proportional), which means that if sodium levels in blood serum are high then diastolic blood pressure will also decrease. Based on the significance test the result shows the $p$-value $=0.015(\mathrm{p}<0.05)$ and so the null hypothesis is rejected, meaning that there is a significant relationship between diastolic blood pressure and sodium. The correlation between diastolic blood pressure and potassium level has a value of $\mathrm{rs}=-0.084$ which can be categorized as having a very weak and negative correlation strength (inversely proportional), which means that if the potassium levels in blood serum are high then diastolic blood pressure will decrease. Based on the significance test, the result shows the $p$-value $=0.468(\mathrm{p}>0.05)$ then the null hypothesis is accepted, meaning that there is no significant relationship between diastolic blood pressure and potassium.

The correlation of diastolic blood pressure and chloride levels has a value of $\mathrm{rs}=-0.090$ which can be categorized as having a very weak and negative correlation strength (inversely proportional), which means that if the chloride levels in blood serum are high then diastolic blood pressure will decrease. Based on the significance test the result shows the $p$-value $=0.448(\mathrm{p}>0.05)$ then the null hypothesis is accepted, meaning that there is no significant relationship 
between diastolic blood pressure and chloride. The correlation of diastolic blood pressure and total calcium levels has a value of $\mathrm{rs}=0.003$ which can be categorized as having a very weak and positive correlation strength (directly proportional), which means that if the total calcium levels in the blood serum are high then the diastolic blood pressure will also increase. Based on the significance test, the result shows the $p$-value $=0.980(\mathrm{p}>0.05)$ then the null hypothesis is accepted, meaning that there is no significant relationship between diastolic blood pressure and total calcium.

\section{Discussion}

Based on the results of this study, it was found that the prevalence of hypertension was more suffered by female compared to male, in which this finding is similar to some previous studies. A cross-sectional study in a rural area in India by Health and Demographic Surveillance System (HDSS) reported that hypertension was more prevalent in older female, which supports the theory indicating the role of endogenous esterogens as protective agents until menopause [15]. In many studies and clinical data have explained that how esterogens in its protector functions for cardiovascular system, including vascular relaxation, inhibition of sympathetic activity, and prevention of vascular remodeling, can reduce stiffness in vascular endothelial, so that eventually can prevent hypertension. As female aged, esterogens levels progressively decline when female nearly reaches perimenopause and post-menopause, so the protective function of esterogens for organs also decreases. Consequently, those effects tend to decline and cause arterial wall stiffness, slacken of nitric oxide production, increase salt sensitivity, and increase angiotensin II receptors activity, where all of these effects are eventually end up with an increase of blood pressure. The above conditions are more likely to be found among females in their post-menopause period than in older males [16].

Age is known as one of the unmodifiable risk factors associated with cardiovascular problems. An increase in blood pressure is directly proportional to age. One of the possible main reasons is an increase of vascular resistance due to increased age causing vascular wall becomes thicker. This change is thought to be associated with cardiovascular problems that can cause a decrease in cardiac output and leads to an increase in the incidence of hypertension in the elderly. In a previous study conducted in Ghana by Acheampong, K. et al, it was reported that the high prevalence of hypertension among people aged $\geq 65$ years compared to people aged 25 - 44 years old, in which this data supports the findings in this study [17].

This study revealed that among the populations over than 18 years up to middle age, only a small amount of the subjects had hypertension. Similar to our findings, Everett, B. et al in their study stated that in general young adults tend to have less awareness of hypertension. This is because of young adults populations are more likely to be healthy and they have a low willingness to do a screening or medically check-up on regular basis [18].

This study showed that the most clinical symptom complained by hypertensive patients is headache $(42.47 \%)$. So far, recent guidelines for hypertension treatment still recommends asking questions about headache for hypertensive patients in physician's practice. Headache symptom in hypertension was well established first by Janeway, in which classic headache in hypertensive patients is characterized by pulsating and uncomfortable painful, experienced first thing in the morning or when wake up from sleep, and can last only for moments [19]. Headache-associated hypertension is a typical symptom and mostly experienced around 50\% hypertensive patients. Headache in severe hypertension is believed to be linked to vascular dilatation, however still lack of evidences available to support the role of pathogenesis of intracranial arterial dilatation that can cause headache in hypertension. There is a hypothesis proposing the mechanism of headache in hypertension, in which the symptom is an outcome of complex interactions among blood pressure systemic, cranial blood flow, ocular autonomic function, ocular choroidal perfusion, and intraocular pressure (IOP), however this still remains lack of evidences and should be further researched [20]. Other literatures explain that morning headache experienced by hypertension patients due to Obstructive Sleep Apnea (OSA) [21], an adverse effect because of consuming anti hypertension drugs causing drugs-induced symptoms, particularly Calcium Channel Blocker (CCB) and vasodilator agents such as hydralazine. However, there lots of hypertensive patients also consumed other drugs that can cause headache, such as nitrates and statins [22]. Nevertheless, the present of headache has no practical consequences in regards of management of hypertension, however headache should also be considered as one of the warning signs but not as a poor mark in treating hypertension itself [19].

Overweight and obese have a tendency as much as twofolds to suffer hypertension compared with other individuals with normal Body Mass Index (BMI). One of the risk factors that can be associated with this problem is dietary habits. In the previous studies aforementioned, reported that females who are not consuming fresh fruit per day are associated with the prevalence of hypertension. Information of fresh fruits intake per day and the risk of hypertension giving an evidence to support the importance of knowledge to know the fresh fruit intake is significantly has positive outcome to prevent hypertension [17]. Nevertheless, physical activity is also has its effect which is possibly thought to have association to this recent study. In previous study by Olack, B. et al reported that female had a tendency to have a high prevalence of hypertension related to lower physical activity patterns than male. Furthermore, that study also reported that BMI $\geq 25 \mathrm{~kg} / \mathrm{m}^{2}$ was to be linked with hypertension, which is similar to our findings in recent study. Being overweight or obese increased the odds of hypertension by $[\mathrm{AOR}=1.7,(95 \% \mathrm{CI}: 1.5-2.7)]$ and $[\mathrm{AOR}=2.0,(95 \% \mathrm{CI}: 1.7-3.4)]$ compared to having normal BMI [23]. This correlates with theory explaining that poor effect of high calorie intake can increase 
norepinephrine levels in peripheral tissue, also resting concentrations norepinephrine plasma, in which these parameters are used to measure the Sympathetic Nervous System (SNS) activity. Therefore, fat contents in foods and carbohydrates can stimulate peripheral $\alpha 1$ and $\beta$-adrenergic receptors, so that can cause increase sympathetic activity and end up with hypertension [24].

In a comprehensive longitudinal analysis study about the changes of blood pressure that measured at least for 3 times per year for 5 years in 3591 subjects, showed no significant correlation between chloride serum effect and systolic blood pressure [25], which is similar to the findings of this study. This study revealed that chloride serum has positive correlation with systolic blood pressure which is directly proportional, however has no significant relationship.

Nowadays, salt intake is thought to be higher because of its use in many foods seasoning, particularly in fastprocessed foods. The mechanism on how salt effect has strong associated towards hypertension is actually because salt, oftentimes, strongly associated with sodium, which is weakly understood by some people. Salt is actually consists of $40 \%$ sodium and $60 \%$ chloride. Replacing administration sodium chloride with sodium citrate only have an effect in increasing plasma volume, meanwhile sodium chloride has its effects to increase the blood pressure. In this recent study, almost $70 \%$ of subjects often consume foods containing salt. There is an inverse correlation between plasma volume and Total Peripheral Resistance (TPR). Higher level of sodium and low level of potassium can inhibit sodium-pump resulting in increase of intracellular sodium and subsequently pushes calcium into cells, and furthermore these pathways induces contraction in vascular smooth muscle and resulting in increase of peripheral vascular resistance [26].

Findings in this recent study is contradictive with a previous study conducted by Yao, Y et al, in China that reported there is a significant positive correlation between calcium serum level and systolic blood pressure in hypertensive patients compared to normotensive people, also calcium serum levels in hypertensive patients tend to be low compared to normotensive people [27]. This is consistent with literature theory that explained how the mechanism of low calcium intake could regulate blood pressure by increasing intracellular calcium in vascular smooth cells resulting in vasoconstriction, also increase in vascular volume through Renin-Angiotensin-Aldosterone System (RAAS). Individuals with low calcium intake can cause decrease calcium plasma concentration, resulting in stimulations for excitation of Parathyroid Hormone (PTH) as its role to balance calcium homeostasis, also synthesis of calcitriol and activation of RAAS. This can cause an activation of some pathways in vasculature, which is activation of Angiotensin II through type I angiotensin II receptors, PTH via protein kinase A, and calcitriol via IP3. These activated pathways resulting in an increase of intracellular calcium concentration which ends up with vasoconstriction and then it continues to increase the peripheral vascular resistance and consequently increase in blood pressure. Another finding by Khan, DM et al, reported that there was no correlation between calcium and diastolic blood pressure in type II diabetes mellitus patients [28].

This study has several limitations, for example, the size of study subjects was not large enough for the results of several electrolytes to be statistically significant. Moreover, calcium intake records were lacking because calcium absorption depends on the age and physiological status of individuals.

\section{Conclusion}

In conclusion, there is significant dirrect correlation between serum sodium levels and systolic blood pressure, and an inverse relationship with diastolic blood pressure. As for potassium, there is an inverse relationship between serum potassium levels with systolic and diastolic blood pressure, but not significant. There is a direct correlation between serum chloride levels and systolic blood pressure, and inverse relationship with diastolic pressure, but not significant. For total calcium, there is a direct correlation between serum total calcium levels and systolic and diastolic blood pressure, but not significant. Further investigation is necessary to identify the role of serum calcium level in populations at different ages.

\section{Conflict of Interest Statement}

All authors declare no conflict of interest.

\section{Acknowledgements}

This study was fully funded by The Directorate Research and Community Service, Sam Ratulangi University, Manado, Indonesia. The authors would like to thank the Department of Biochemistry Faculty of Medicine, Sam Ratulangi University and the Noongan Regional General Hospital for all the supports. Last but not least, the authors are so deeply honored to thank everyone who has participated in this study.

\section{References}

[1] Egan BM. Defining Hypertension by Blood Pressure 130/80 $\mathrm{mm} \mathrm{Hg}$ Leads to an Impressive Burden of Hypertension in Young and Middle-Aged Black Adults: Follow-Up in the CARDIA Study. J Am Heart Assoc. 2018; 7 (14): 1-3.

[2] Drozdz D, Kawecka-Jaszcz K. Cardiovascular Changes During Chronic Hypertensive States. Pediatr Nephrol. 2014; 29 (9): 1507-16.

[3] Singh S, Shankar R, Singh GP. Prevalence and Associated Risk Factors of Hypertension: A Cross-Sectional Study in Urban Varanasi. Int J Hypertens. 2017; 2017: 5491838.

[4] Tabrizi JS, Sadeghi-Bazargani H, Farahbakhsh M, Nikniaz L, Nikniaz Z. Prevalence and Associated Factors of Prehypertension and Hypertension in Iranian Population: The Lifestyle Promotion Project (LPP). PLoS One. 2016; 11 (10): e0165264. 
[5] Patnaik L, Paul KK, Pattnaik S, Sahu T. Lifestyle Pattern and Hypertension Related Knowledge, Attitude and Practices among Diagnosed Patients of Hypertension Attending a Tertiary Care Hospital. J Cardiovasc Dis Res. 2017; 8 (4): $108-111$.

[6] Diana DAIAT, Astini DAAAS. Prevalence of Hypertension Among Adults in Kintamani Subdistrict-Bali. IOP Conference Series: Materials Science and Engineering. 2018; 434: 012322 .

[7] Kementerian Kesehatan RI Badan Penelitian dan Pengembangan Kesehatan. Riset Kesehatan Dasar. Prevalensi Hipertensi Berdasarkan Diagnosis Dokter atau Minum Obat Antihipertensi Pada Penduduk Umur $\geq 18$ Tahun Menurut Provinsi, 2018.

[8] Dinas Kesehatan Daerah Provinsi Sulawesi Utara. Profil Kesehatan Provinsi Sulawesi Utara 2016. Pengukuran Tekanan Darah Penduduk $\geq 18$ Tahun Menurut Jenis Kelamin, Kabupaten/Kota Provinsi Sulawesi Utara. 2017.

[9] Balci AK. General Characteristics of Patients with Electrolyte Imbalance Admitted to Emergency Department. World J Emerg Med. 2013; 4 (2): 113-6.

[10] Forjaz CLM, Bartholomeu T, Rezende JAS, Oliveira JA, Basso L, Tani G, et al. Genetic and Environmental Influences on Blood Pressure and Physical Activity: A Study of Nuclear Families from Muzambinho, Brazil. Braz J Med Biol Res. 2012; 45 (12), 1269-75.

[11] Opoku-Okrah C, Safo BK, Dogbe EE. Changes in Potassium and Sodium Concentrations in Stored Blood. Pan Afr Med J. 2015; 20: 236.

[12] Bolívar JJ. Essential Hypertension: An Approach to Its Etiology and Neurogenic Pathophysiology. Int J Hypertens. 2013; 2013: 547809.

[13] Lynch, R. 2018 ESC/ESH Guidelines for The Management of Hypertension. J Hypertens. 2018; 36 (10): 89.

[14] Bell K, Twiggs J, Olin BR. Hypertension: The Silent Killer: Updated JNC-8 Guideline Recommendations. Alabama Pharmacy Association. 2015.

[15] Ghosh S, Mukhopadhyay S, Barik A. Sex Differences in The Risk Profile of Hypertension: A Cross-Sectional Study. BMJ Open. 2016; 6 (7): e010085.

[16] Ahmad A, Oparil S. Hypertension in Female: Recent Advances and Lingering Questions. Hypertension. 2017; 70 (1): 19-26.
[17] Acheampong K, Nyamari JM, Ganu D, Appiah S, Pan X, Kaminga A, et al. Predictors of Hypertension among Adult Female Population in Kpone-Katamanso District, Ghana. Int J Hypertens. 2019: 1-9.

[18] Everet B, Zajacova A. Gender Differences in Hypertension and Hypertension Awareness Among Young Adults. Biodemography Soc Biol. 2015; 61 (1): 1-17.

[19] Courand PY, Serraille M, Girerd N, Demarquay G, Milon H, Lantelme P, et al. The Paradoxical Significance of Headache in Hypertension. Am J Hypertens, 2016; 29 (9): 1109-16.

[20] Gupta VK. Systemic Hypertension, Headache, and Ocular Hemodynamics: A New Hypothesis. MedGenMed. 2006; 83 (3): 63 .

[21] Handler J. Headache and Hypertension: Primary or Secondary? J Clin Hypertens. 2007; 6 (1): 42-4.

[22] Yeung A. What is The Connection Between Hypertension, Headache and Migraine? Canadian Hypertension Society. 2006; 87: 1-8.

[23] Olack B, Wabwire-Mangen F, Smeeth L, Mongomery JM, Kiwanuka N, Breiman RF. Risk Factors of Hypertension Among Adults Aged 35-64 Years Living in Urban Slum Nairobi, Kenya. BMC Public Health, 2015; 15: 1251.

[24] Jiang SZ, Lu W, Zong XF, Ruan HY, Liu Y. Obesity and Hypertension. Exp Ther Med. 2016; 12 (4), 2395-9.

[25] McCallum L, Jeemon P, Hastie CE, Patel RK, Williamson C, Redzuan AM, et al. Serum Chloride Is an Independent Predictor of Mortality in Hypertensive Patients. Am Heart J. 2013; 62 (5): 836-43.

[26] Frisoli TM, Schmieder RE, Grodzicki T, Messerli FH. Salt and Hypertension: Is Salt Dietary Reduction Worth the Effort? Am J Med. 2012; 125 (5): 433-9.

[27] Yao Y, He L, Jin Y, Chen Y, Tang H, Song X, et al. The Relationship Between Serum Calcium Level, Blood Lipids, and Blood Pressure in Hypertensive and Normotensive Subjects who Come from a Normal University in East China. Biol Trace Elem Res. 2013; 153 (1-3): 35-40.

[28] Khan DM, Khan IM, Randhawa FA, Shahid M. Correlation between Serum Calcium Level with Blood Pressure Level In Patients Presenting With Type 2 Diabetes Mellitus. Esculapio. 2017; 13 (1): 18-21. 